\title{
Editorial
}

\section{Electronic journals}

\section{Introduction}

This special issue starts with an article from the British Library and continues with articles by librarians in UK universities who are dealing with the problems and successes of introducing and managing electronic journals. They are written by people with "hands on" experience.

The rate of change in this field is very rapid so that the contents of many of the references provided by the authors may have been overtaken by events. This issue itself is valuable because it is as up to date as the compose/publishing cycle permits. It is unfortunate that the book by Tenopir and King, which seems to be regarded as the standard work on the subject, is also getting a little out of date, although it was published in 2000 [2].

In this editorial an attempt will be made to highlight the major issues discussed by authors in this issue. As might be expected, a number of themes are common to many of the articles.

\section{Advantages}

At one author's university, electronic journals are the most popular means of accessing the literature. Most universities receive at least 3000 of them.

In one University over 200,000 full text articles were downloaded in the first eight months of the 2000 to 2001 academic year.

Another author says: "It seems likely that we will move to electronic only access but not just yet." Others claim various advantages: "Convenience is a major factor ... the prevalence of home computers with Internet connection is a key enabling factor in access policy. Many students study away from the university campus." The reduction in the cost and work involved in binding and storing a large quantity of journal volumes is another factor which will become important, if the trend which seems to be in progress, for printed journals to be replaced by a electronic journals continues.

\section{Disadvantages}

While there seems to be general enthusiasm about the adoption of electronic journals, some authors are still doubtful. One problem is the limited amount of back runs which are available. Another thinks that electronic journals are "in transition", but that opinions may change. "It would be unwise to discard print at present." There is an almost universal complaint about the fact that electronic journals are subject to Value Added Tax (VAT) - a library expense not previously there. "The VAT levied on electronic but not printed material is a disincentive for electronic only use." 
The recording of the holdings and use of electronic journals needs to be improved. "Information about holdings, control, and the amount of use of electronic journals is poor. It would cost $£ 1$ million annually to get it right." and "The collection of comparable usage statistics is a major unsolved issue of the market."

There seems to be some unease about submitting articles for publication. In one University "the majority prefer to publish in journals available both in print and electronic versions". In another, potential authors believe that printed journals are "more significant". Electronic journals are less acceptable. One author has doubts about journals in general. She considers that "the future of electronic journals and journals in general is uncertain".

There is considerable comment about the difficulty of reading from the screen and about the quality of material printed from electronic journals. One author reports on "frustration with printed quality by over 50 per cent of respondents to a survey".

\section{Needs}

In one article the most wanted feature mentioned is a link from bibliographic references to the full text from electronic journals. Another requirement is "the removal of site access restrictions which work against distance learning students ... there are model licences which allow it".

\section{Prices}

Complaints about prices is one of the most dominant themes. The Americans are more outspoken than the English. Emily Mobley, dean of libraries at Purdue University speaks her mind: "Over the last few years, almost open warfare has broken out between academic librarians and commercial scholarly or sci-tech publishers. While the librarians face fixed or declining budgets as well as rising demands for digital services, the publishers continue to rack up double-digit annual profit percentages" [3]. An author in this issue says: "We cannot afford to be punished financially ... ways must be found to purchase those electronic titles we need most at reasonable cost."

A perceptive comment about prices is made by another of our authors: "The library profession carries the user in its conscience even when dealing with publishers who carry less emotional baggage. Brinkmanship and bargaining sit more easily on the shoulders of the publishers ...."

Yet another says: "There is an identifiable tension between the typical funding modes driven by institutional culture and structures ... and the volatile commercially driven electronic information product ... affordability and value for money is of key importance ... unbundling of print and electronic subscriptions and the ability to cancel print with appropriate savings [is required]."

Mark McCabe, an economist at the Georgia Institute of Technology, provides an example. He asks how a doubling of the price of Elsevier's Brain Research to \$15,000 annually between 1992 and 1996 can be justified. McCabe says that Elsevier Science was unavailable for comment, but this writer had no difficulty in obtaining a comment from a Mr Spiteri at Elsevier Science. He said that the Journal had increased in size is during the period and the price increase had been about $4 \%$ per annum.

Two organisations are working in order to improve scholarly communication. The objective of the Scholarly Publishing and Academic Resources Coalition (SPARC) is, among others, to "encourage the introduction of alternative scientific communication outlets of high-quality and fair price". SPARC helped to launch the Royal Society of Chemistry's PhysChemComm. It's British counterpart, Consortium of University Research Libraries (CURL) has similar objectives. 


\section{The library professionals}

It is a sad fact that in the minds of their clients and the general public, librarians do not have an image which properly conveys their ability. It is obvious from these articles that librarians are very capable they are rising to the challenge. The "electronic librarian" is a skilled knowledgeable person. How can the profession do something to convey this image to the public at large? Is it doing and does it want to do anything? The librarians role has been discussed by Rowland [4].

In one University it has been found necessary to appoint an "electronic journals co-ordinator", in another "an electronic resources librarian". The selection, ordering, and acquisition of electronic journals is far more complex than print. "It forces librarians to make decisions they have never had to make before," says another. "My job has expanded ... the advent of e-journals and the associated changes and possibilities within the process of scholarly communication ... have made this a fascinating and exciting sector." Library professionals have found it necessary to market the changes. "If there is no marketing there is no use of the information services provided." At the same time they are aware of the dangers. "Librarians must avoid being marginalised when electronic delivery becomes the norm."

\section{Changes in the publishing model}

An author in this issue mentions the current controversy about the present model of scholarly communication. CURL is quoted as being one of the organisations that are looking into the matter. "This will include the establishment of alternatives and significantly less expensive titles to current lead journals in research fields published by, for instance, Elsevier. There will be a concerted effort to ask HEI's to consider the question of intellectual property rights in a move to stop the current situation where the results of research are given to publishers. Libraries then have to pay to gain access to this information either through subscription costs or through IIL charges or CLA fees. A third strand may soon be the introduction of open archive initiatives which will establish e-print archives on an institutional or subject basis."

However it should be remembered that the present publishing model in which important journals rise to the top, is part of the social fabric of Science. If the model is changed, or the arrival of electronic journals affects "pecking orders" or archival records, it could affect this fabric. Its importance may be gauged by the events associated with the discovery of the double helix by Watson and Crick. They cleared the decks with the editor of Nature for rapid publication of their research results [5] to establish discovery priority. They suspected that Pauling would soon announce a similar discovery. Their paper occupied a single page of Nature (citations to it are now approaching 3000). It contained a profound statement about genetics: "The specific pairing we have postulated immediately suggests a possible copying mechanism for the genetic material." Both authors received the Nobel prize.

A.E. Cawkell

\section{References}

[1] D. Butler, The writing on the wall for books in print, Nature 397 (2000), 195-200.

[2] T. Cawkell, Book review: "Carol Tenopir and Donald King, Towards electronic journals: realities for scientists, librarians, and publishers, Special Libraries Association, Washington, 2000", in: Journal of Documentation 57(5) (2001), 708-713.

[3] B. Quint, Emily Mobley: interview with a rebel leader, Searcher 7(8) (1999), 41-46. 
[4] F. Rowland, The librarians role in the electronic information environment (1998), available at www.bodley.ox.ac.uk/ icsu/rowlandppr.

[5] T.J. Watson and F.H.C. Crick, Molecular structure of nucleic acid, Nature 4536 (1953). 